\title{
ĐÁNH GIÁ TỔNG QUAN ĐĂC NHIÊMM SỨC KHỎE TÂM SINH LÝ CỦA LỰC LƯợNG Bộ ĐộI ĐẶC THÙ
}

\author{
Lê Văn Quang1, Nguyễn Hồng Quang1, Bùi Thị Hương1, \\ Trần Thị Nhài ${ }^{1}$, Lê Văn Cường ${ }^{1}$, Cao Trung Thành ${ }^{1}$, \\ Trần Thu Trang ${ }^{1}$, Nguyễn Trọng Nghĩa ${ }^{2}$, Lê Văn Quân ${ }^{3}$.
}

\section{TÓM TẮT}

Mục tiêu: Phân tích tình hình sức khỏe tâm sinh lý của lực lượng bộ đội đặc thù. Phương pháp: Thuân tập hồi cứu. Kết quả: Các lực lượng bộ đội đặc thù có đặc điểm chung về điều kiện môi trường làm việc như: Tiếng ồn lớn, nhiệt độ cào, công việc vất vả, căng thẳng. Ngoài yếu tố chưng về đặc điểm chung về môi trường làm việc, thì mỗi đơn vị riêng biệt có những yếu tố ảnh hưởng đặc trưng tác động lển sức khỏe của bộ đội đặc thù như sau: Bộ đội radar: chịu ảnh hưởng rõ rệt của sóng radar; Phi công quân sự: yếu tố ảnh hưởng lớn nhất là âm thanh Iớn; Thủy thủ tàu ngầm: khồng gian làm việc ngột ngạt, thiếu ánh sáng, có hơi khí độc và công việc căng thẳng. Kết luận: Đặc điểm chung của Bộ đội đặc thù có điêu kiện làm việc: khó khăn, vất vả và trách nhiệm cao. Cácđơn vị bộ đội cũng có đặc điểm môi trường hoạt động riêng biệt, điều này dẫn đến mối đơnn vị có đặc điểm về cớ cấu bệnh tật cũng như đặc điểm sức khỏe tâm sinh lý khác nhau.

Tư khóa: Sức khỏe tâm sinh lý, điều kiện môi trường hoạt động, phi công quân sự, bộ đội radar, thủy thủ tàu ngâm.

\section{SUMMARY}

GENERAL CHRACTERISTICS OF METAL HEALTH IN SPECITAL MILITARY SOLDIERS

Objective: to analyze situation of mental health in special military soldiers. Methods: Historical cohort study. Results: special military soldiers were affected by some environmental factors, including: Noisy, high environmental temparature, working, stress. However, each special military unit also were affected by specific factors. Radar soldiers were related to radar signals, military pilots were related to noisy and atmospheric pressure, Submarine sailor were related to cramped environment, darkness, poisonous gas and stress. Conclusion: Each military unite were effected by many specific environment factors. Thus, there were some difference in characteristics of mental health of each military units.

Keywords: Mental health, specific environment factors, radar soldiers, military pilots, submarine sailor

\section{I. ĐẶT VẤN ĐỀ}

\footnotetext{
${ }^{1}$ Viện Y sinh nhiệt đới/Trung tâm Nhiệt đới Việt-Nga 2Bệnh viện Trung Ương Quân đội 108

3Bệnh viện Quân y 103, Học viện Quân y

Chịu trách nhiệm chính: Lể Văn Quang

Ngày nhận bài: 5/9/2021

Ngày phản biện khoa học: 5/10/2021

Ngày duyệt bài: 20/10/2021
}

Lực lượng quân sự đặc thù như phi công quân sự, bộ đội ra đá, bộ đội tàu ngầm ngoài những đặc điểm chung như cường độ lao động cao còn có nhiều đặc điểm riêng như phi cồng quân sự chịu áp lực không khí, bộ đội ra đa chịu tác động của từ trường điện tử hay bộ đội tàu ngầm chịu tác động của ánh sáng kém, tiếng ồn Iớn và nhiệt độ cao. Nhiều nghiên cứu đã chỉ ra rằng những yếu tố đặc thù nói trên cùng với cường độ lao động cao của hoạt động quân sự là yêu tố nguy cơ của rất nhiều bệnh lý khác nhau như bệnh tim mạch, bệnh thính giác, bệnh thị giác [3]. Đặc biệt, gần đây, một nghiên cứu ở Trung tâm Việt Nga còn cho thẩy những yếu tố môi trường trong hoạt động quân sự của lực lượng bộ đội đặc thù còn ảnh hưởng rất lớn đển sức khỏe tâm lý của đội đội [1]. Tuy nhiên, những nghiên cứu này vẫn chưa đưa ra được mối liên quan rõ rệt về yếu tố môi trường quẩn sự lên sức khỏe tâm lý của từng loại bộ đội đặc thù. Vì vậy, chúng tôi thực hiện nghiên cứu này nhằm mục đích phân tích đặc điểm môi trường hoạt động lao động đặc thù của từng đối tượng và phân tích sự ành hưởng của những yếu tố này lên sức khỏe tâm lý của từng lực lượng bộ đội đặc thù.

\section{II. ĐỐI TƯỢNG VÀ PHƯƠNG PHÁP NGHIÊN CỨU}

2.1. Đối tượng nghiên cứu: Bao gồm 3 lực lượng: 160 phi công quân sự, 100 bộ đội ra đa và 166 thủy thủ tàu ngầm.

\subsection{Phương pháp nghiên cứu}

2.2.1. Thiết kế nghiên cứu. Nghiên cứu thuần tập hồi cứu kết hợp phân tích đặc điểm tâm sinh lý đối tượng nghiên cứu tại thời điểm trước, sau khi thực hiện nhiệm vụ.

2.2.2. Phương pháp thu thập số liệu. Tổng hợp dữ liệu đã nghiên cứu về các lực lượng bộ đội đặc thù tại Trung tâm Nhiệt đới Việt Niga trong giai đoạn 2017-2020. Trên cơ sở nhứng dữ liệu đã tổng hợp, phân tích đặc điểm sức khỏe tẩm sinh lý đặc trưng và ảnh hưởng của yếu tố môi trường hoạt động quân sự tới sức khỏe tâm sinh lý của bộ đội đặc thù (bộ đội radar, bộ đội tàu ngầm, phi công quân sự').

2.3. Xử lý số liệu. Các số liệu nghiên cứu được xử lý bằng máy vi tính trền phần mềm 
Excel 2013, IBM SPSS Statistics 20 theo phương pháp thống kê y sinh học. Kết quả được thể hiện dưới dang:

- Số trung bình $(\mathrm{X})$, độ lệch chuẩn (SD), tỷ lệ phần trăm $(\%)$ và $p<0,05$.

- Phương pháp kiểm định T-test và One way Anova được sử dụng để so sánh các nhóm giá trị. Giá trị khác biệt có ý nghĩa thống kê với p<0,05.

\section{KẾT QUẢ NGHIÊN CỨU}

\section{1. Đặc điểm môi trường hoạt động và sức khỏe của bộ đội radar \\ 3.1.1. Yếu tố môi trường hoạt động của bộ đội radar}

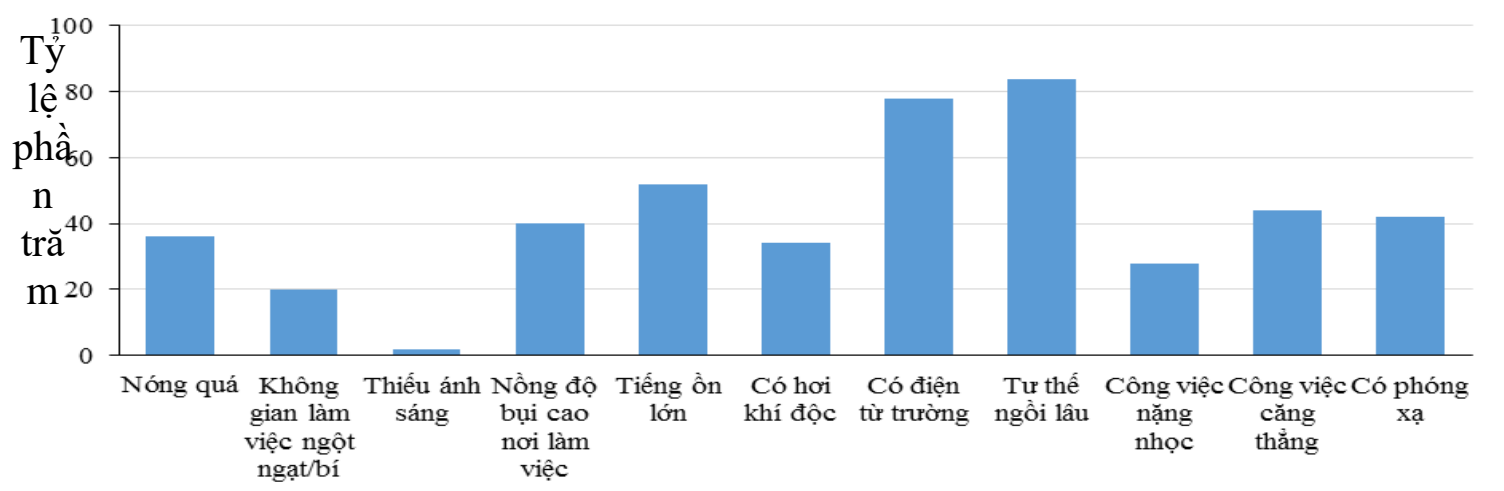

Biểu đồ 1. Yếu tố môi trường hoạt động của bộ đội radar

Nhận xét: Kết quả Biểu đồ 1 cho thấy, mặc dù bộ đội ra đa chịu nhiều tác động của yếu tố môi trường hoạt động nhưng đặc điểm đặc trưng (những yếu tố chiếm tỷ lệ trên $40 \%$ ) của yếu tố môi trường này là: công việc căng thẳng (chiếm $44 \%$ ), có phóng xạ (chiếm 42\%), đặc biệt 2 yếu tố chiếm tỷ lệ cao hơn các yếu có khác và có sự khác biệt đạt ý nghĩa thống kê (với $p<0.05$ ) là: có điện từ trường (chiếm $78 \%$ ) và tư thế ngồi lâu (chiếm 84\%).

3.1.2. Suy giảm trang thái chức năng cơ thể của bộ đội radar trước và sau khi thực hiện nhiệm vu

Bảng 1. Sự thay đôi các chỉ số chức năng cơ thể trước và sau ca trực của trắc thủ

\begin{tabular}{|c|c|c|}
\hline Chỉ số Thời gian & Trước & $\begin{array}{l}\text { Sau } \\
\text { trưc }\end{array}$ \\
\hline
\end{tabular}

\begin{tabular}{|c|c|c|}
\hline Nhịp tim. nhịp/phút & $78,0 \pm 3,0$ & $71,0 \pm 3,0$ \\
\hline Thới gian phàn xạ với & $276,0 \pm$ & $278,0 \pm$ \\
ánh sáng vàng (ms) & 4,0 & 7,0 \\
\hline Tỉ lệ phản xa chính xác & $26.7 \pm$ & $27.1 \pm$ \\
với mục tiêu di động(\%) & 2.5 & 1.5 \\
\hline
\end{tabular}

Nhẩn xét: Kết quả Biểu đồ 2 đánh giá sự thay đổi các chỉ số chức năng cơ thể sau ca trực của trắc thủ. Kết quả cho thấy sau ca trực nhịp tim của bộ đội ra đa đã giảm có ý nghĩa thống kê $(p=0,032)$. Ngoài ra, sau ca trực bộ đội ra đa có tỷ lệ phản xạ chính xác với mục tiêu di động tăng lên mặc dù không có sự khác biệt đạt ý nghĩa thống kề. Điều đó cho thấy đã có sự thích ứng tâm lý sau ca trực của bộ đội ra đa. Tuy nhiên, thời gian phản xạ với ánh sáng màu vàng lại dài hơn, chứng tỏ đã có sự suy giảm về trạng thái chức năng cơ thể.

\subsection{3. Đặc điểm trạng thái chức năng cơ thể của bộ đội radar}

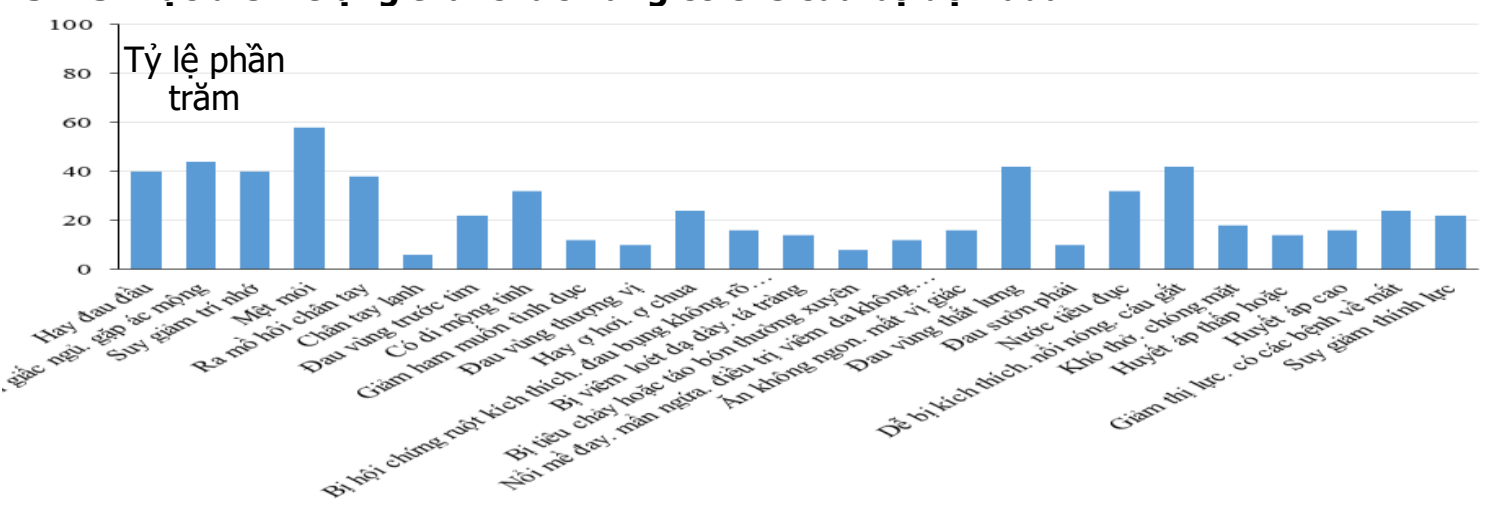

Biểu đồ 2. Cơ cấu bệnh tật của bộ đội ra đa 
Nhận xét: Đặc điểm cơ cấu bệnh tật của bộ đội ra đa được thể hiện qua Biểu đồ 2. Ta thấy, các bệnh điển hình (chiếm tỷ lệ trên $30 \%$ ) liên quan đến cơ cấu bệnh tật của lực lượng bộ đội ra đa là: hay đau đầu (chiếm 40\%), ngủ gặp ác mộng (chiếm 44\%), suy giảm trí nhớ (chiếm $40 \%$ ), mệt mỏi (chiếm 58\%), ra mồi hôi chân tay (chiếm 38\%), di mộng tinh (chiếm 32\%), đau vùng thắt lưng (chiếm $42 \%$ ), nước tiểu đục (chiếm $32 \%$ ) và dễ bị kích thích, cáu gắt (chiếm $42 \%$ ). Kết quả này là tương đồng với các nghiên cứu trước đây [8].

\section{2. Đặc điểm môi trường hoạt động và sức khỏe của phi công quân sự \\ 3.2.1. Yếu tố môi trường hoạt động của phi công quân sự}

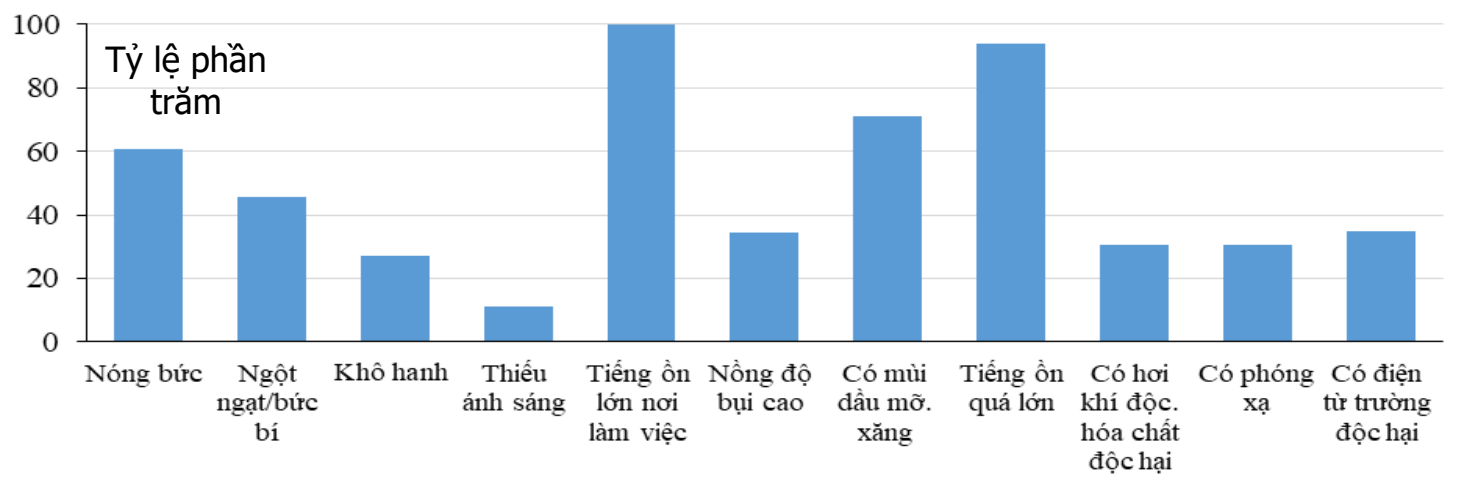

Biểu đồ 3. Yếu tố môi trường hoạt động của phi công quân sưr

Nhận xét: Kết quả Biểu đồ 3 cho thây, đối với lực lượng phi công quân sự chịu nhiều yếu tố bất lợi trong quá trình hoạt động nghề nghiệp, tuy nhiên các yếu đặc trưng (chiếm tỷ lệ trên 40\%) của lực lượng này là: nhiệt độ không khí nơi làm việc nóng bức (chiếm $61 \%$ ), không gian làm việc ngột ngạt (chiếm 45\%), căng thẳng (chiếm $41 \%$ ). Các yếu tố tiếng ôn lớn nơi làm việc (chiếm $100 \%$ ), môi trường làm việc chứa nhiều mùi dầu mõ (chiếm $741 \%$ ) và ảnh hưởng tiêu cực của tiếng ôn động cơ máy bay (chiếm 94\%) chiếm tỷ lệ cao nhấtvà có sự khác biệt đạt ý nghĩa thống kê so với các yếu tố còn lại ( $p<$ $0.05)$.

3.2.2. Suy giảm trạng thái chức năng cơ thể của phi cống quân sự trước và sau khi thực hiện nhiệm vụ
Bảng 2. Trạng thái chức năng cơ thể của phi công quân sự trước và sau khi thực hiện nhiệm vụ

\begin{tabular}{|c|c|c|}
\hline Thời giar & Trt & Sau ba \\
\hline Nhịp tim. nhịp/phút & $71.4 \pm 3.1$ & $87.0 \pm 3.1$ \\
\hline $\begin{array}{l}\text { Thời gian phản xạ với ánh } \\
\text { sáng vàng (ms) }\end{array}$ & $\begin{array}{l}258.5 \pm \\
8.7\end{array}$ & $\begin{array}{l}285.8 \pm \\
12.7\end{array}$ \\
\hline $\begin{array}{l}\text { Tỉ lệ phản xa chính xác với } \\
\text { mục tiêu di động (\%) }\end{array}$ & $\begin{array}{l}39.2 \\
\pm 7.6\end{array}$ & $\begin{array}{l}38.3 \\
\pm 6.5\end{array}$ \\
\hline
\end{tabular}

Nhận xét: Bảng 2 cho thấy đã có sự thay đổi đạt ý nghĩa thống kê $(P<0.05)$ các chỉ số ở thời điểm trước và sau khi bay. Cụ thể, nhịp tim tăng từ 71,4 nhịp/phút lên 87 nhịp/phút, phi công quân sự có tốc độ phản ứng với ánh sáng vàng dài hơn từ 258,5 ms lên 285,8 ms, và tỷ lệ phản xạ đúng với mục tiêu di động giảm từ 39,2 \% xuống 38,3\%.

\subsection{3. Đặc điểm trạng thái chức năng cơ thể của phi công quân sự}

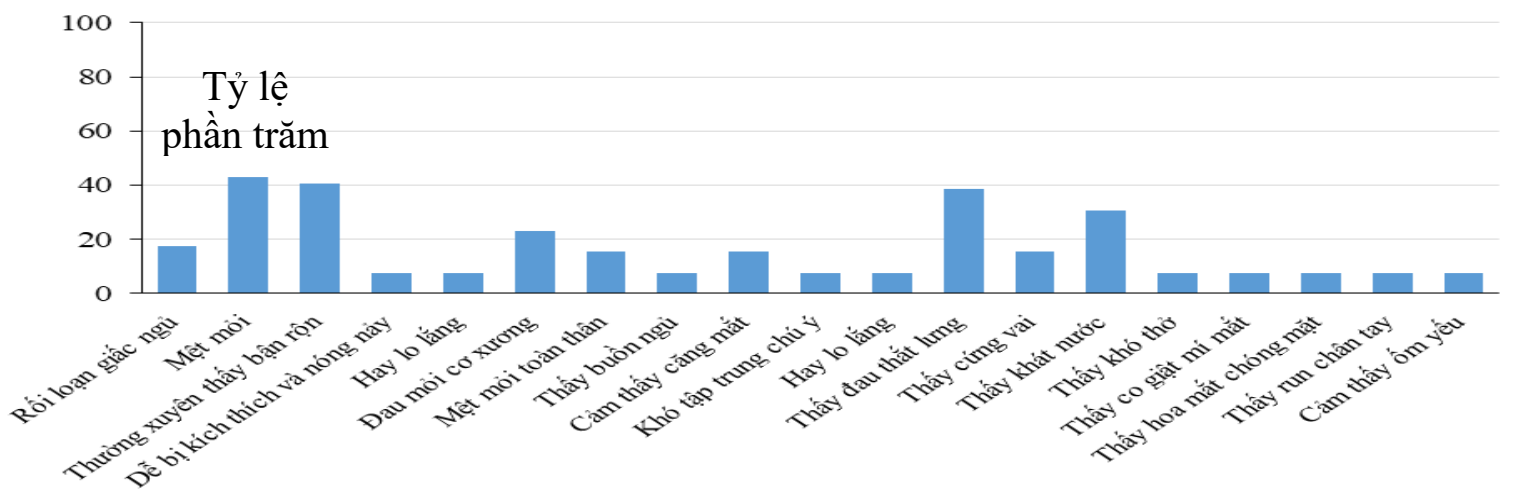

Biểu đồ 4. Cơ cấu bệnh tật của phi công quân sự 
Nhận xét: Biểu đồ 4 cho thấy, các bệnh đặc trưng (chiếm tỷ lệ trên 20\%) đối với lực lượng phi công quân sự là: mệt mỏi (chiếm 43,08\%), thường xuyên thấy bận rộn (chiếm 40,77\%), đau mỏi cơ xương (chiếm 23.08\%), đau thắt lưng (chiếm 38.46\%), và thấy khát nước (chiếm 30.77\%).

\section{3. Đặc điểm môi trường hoạt động và sức khỏe của thủy thủ tàu ngâm}

\subsubsection{Yếu tố môi trường hoật động của thủy thủ tàu ngầm}

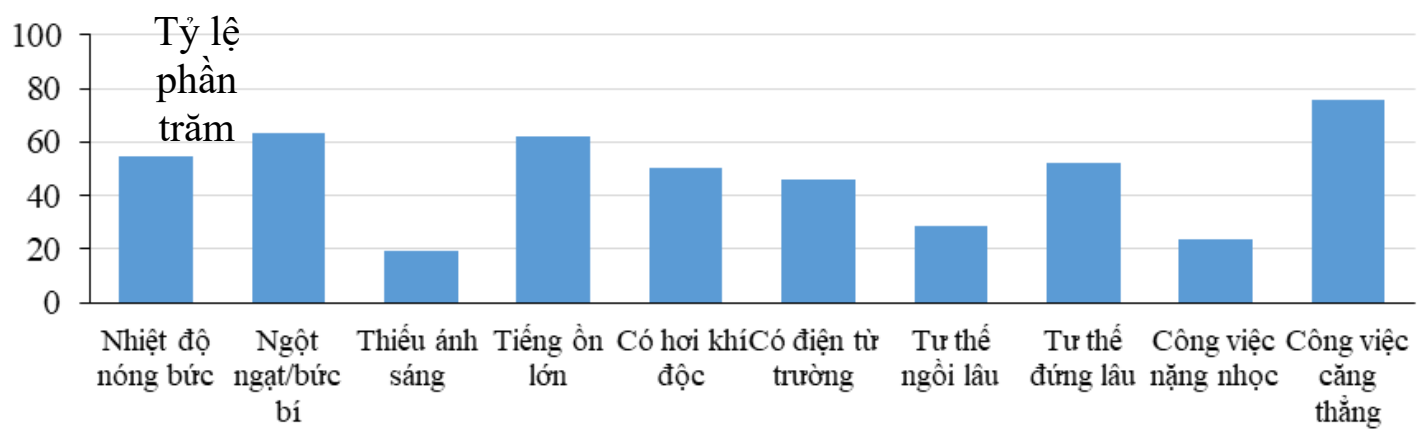

Biểu đồ 5. Yếu tố môi trường hoạt động của thủy thủ tàu ngầm

Nhân xét: Biểu đồ 5 cho thây, các yếu tố hoạt động nghề nghiệp đặc trưng của thủy thủ tàu ngầm là: nhiệt độ nóng bức (chiếm 54.8\%), ngột ngạt/bức bí (chiếm 63.3\%), tiếng ồn lớn (chiếm $62 \%$ ), có hơi khí có độc (chiếm $50.6 \%$ ), có điện từ trường (chiếm $45.8 \%$ ), tư thế đứng lâu (chiếm $52.4 \%$ ) và công việc cẳng thẳng (75.9\%).

3.3.2. Suy giảm trạng thái chức năng cơ thể của thủy thủ tàu ngâm trước và sau khi thực hiện nhiệm vụ

Bảng 3. Trạng thái chức năng cơ thể của phi công quân sự trước và sau khi thực hiện nhiệm vụ

\begin{tabular}{|c|c|c|}
\hline \multicolumn{1}{|c|}{ Thời gian } & Trước ca & Sau ca \\
\hline Chỉ số & $80.45 \pm 3.15$ & $71.20 \pm 2.42$ \\
\hline Thời tim. nhian phạn xạ với ánh sáng vàng $(\mathrm{ms})$ & $483.82 \pm 47.4$ & $468.10 \pm 33.10$ \\
\hline Tỉ lệ phản xạ chính xác với mục tiêu di động (\%) & $64.00 \pm 0.12$ & $69 \pm 0.09$ \\
\hline
\end{tabular}

Nhận xét: Kết quả bảng 3 cho thấy, lực lượng thủy thủ tàu ngầm cũng tương tự như bộ đội ra đa có sự suy giảm nhịp tim sau khi thực hiện nhiệm vụ. Nhưng thời gian phản xạ với kích thích thị giác và kích thích âm thanh lại tốt hơn sau khi thực hiện nhiệm vụ. Cụ thể thời gian phản xạ với kích thích ánh sáng nhanh hơn ( từ 483,82ms xuống 468,1ms), tỷ lệ phản ứng chính xác với kích thích âm thanh tăng từ $64 \%$ lên $69 \%$.

\subsection{So sánh đặc điểm môi trường hoạt động của 3 lực lượng bộ đội đặc thù}

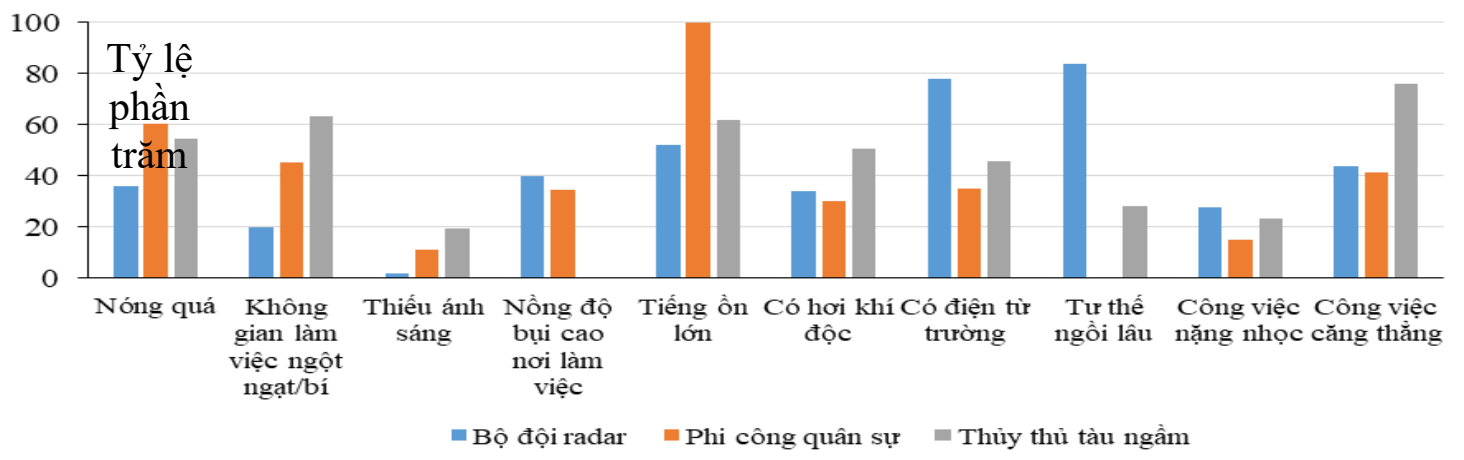

Biểu đồ 6. So sánh môi trường làm việc

Nhận xét: Từ kết quả các biểu đồ trên ta thấy mỗi lực lượng bộ đội đặc thù có các yếu tố môi trường hoạt động đặc trưng khác nhau. Cùng với đó, kết quả Biểu đồ 6 cho thấy đối với bộ đội ra đa có các yếu tố môi trường hoạt động cao hơn các lực lượng khác là: nồng độ bụi cao nơi làm việc, có điện từ trường. Đối với lực lượng phí công quân sự các yếu tố: nhiệt độ nợi làm việc nóng quá, tiếng ôn lớn chiếm tỷ lệ cao hơn 2 lực lượng còn lại. Thủy thủ tàu ngầm yếu tố môi trường hoạt động đặc 
trưng chiếm tỷ lệ cao hơn các lực lượng khác là: không gian làm việc ngột ngạt, thiếu ánh sáng, có hơi khí độc và công việc căng thẳng.

\subsection{So sánh đặc điểm trạng thái chức năng cơ thể của bộ đội đặc thù}

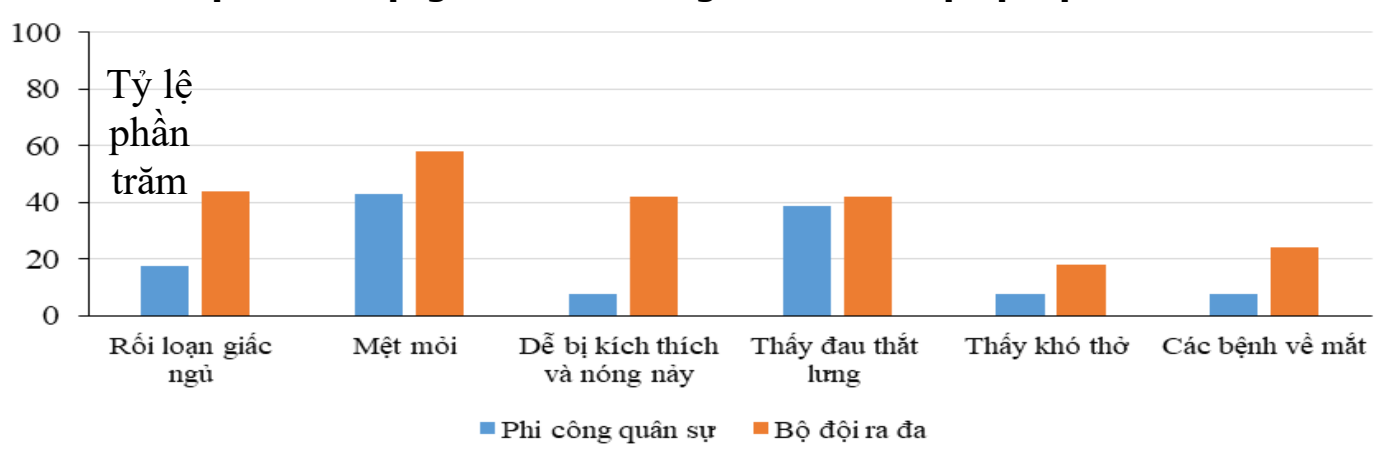

Biểu đồ 7. So sánh đặc điểm trạng thái chức năng cơ thể

Nhận xét: So sánh cơ cấu bệnh tật (các mặt bệnh được nghiên cứu giống nhau) giữa hai lực lượng bộ đội ra đa và phi công quân sự được biểu hiện thông qua Biểu đồ 7. Ta thây, mặc dù hầu hết các bệnh được thể hiện trong biểu đồ là các bệnh đặc trưng cho hai lực lượng bộ đội ra đa và phi cổng quân sự, nhưng đối với lực lượng bộ đội ra đa đều chiếm tỷ lê cao hơn đối với lực lượng phi công quân sự. Thồng qua cơ cấu bệnh này cũng thây rằng, các bệnh này hầu như liên quan đến bệnh liên quan đến thần kinh. Như vậy, đối với lực lượng ra đa bị ảnh hưởng các sóng cao tần của máy phát ra đa gây nên các bệnh liên quan đến thần kinh trầm trọng hơn các lực lượng khác.

\section{BÀN LUẬN}

Kết quả trong nghiên cứu này đã chỉ ra, Bộ đội ra đa có đặc trưng môi trường hoạt động nghề nghiệp là: công việc căng thẳng, có phóng xạ, đặc biệt 2 yếu tố chiếm tỷ lệ cao hơn các yếu có khác và có sự khác biệt đạt ý nghĩa thống kê là: có điện từ trường và tư thể ngồi lâu. Điều này dẫn đến cơ cấu bệnh tật đặc trưng của lực lượng này là: hay đau đầu, ngủ gặp ác mộng, suy giảm trí nhớ, mệt mỏi và dễ bị kích thích, cáu gắt. Đây là các mặt bệnh liên quan đến sự ảnh hưởng của sóng ra đa đến hoạt động của thần kinh.

Đối với phi công quân sự, yếu tố hoạt động môi trường đặc trưng là: nhiệt độ không khí nơi làm việc nóng bức, không gian làm việc ngột ngạt, căng thẳng. Các yếu tố tiếng ồn lớn nơi làm việc, môi trường làm việc chứa nhiều mùi dầu mõ và ảnh hưởng tiêu cực của tiếng ồn động cơ máy bay chiếm tỷ lệ cao nhất và có sự khác biệt đạt ý nghĩa thống kê so với các yếu tố còn lại $(p<0.05)$. Tương ứng với tính chất môi trường hoạt động này cơ cấu bệnh tật cũng chỉ ra có sự tương quan đó là các mặt bệnh đặc trưng là: mệt mỏi, thường xuyên thấy bận rộn, đau mỏi cơ xương, đau thắt lưng, và thây khát nước.

Thủy thủ tàu ngầm có các yếu tố môi trường hoạt động đặc trưng như sau: nhiệt độ nóng bức, ngột ngạt/bức bí, tiếng ồn lớn, có hơi khí có độc, có điện từ trường, tư thế đứng lâu và công việc căng thẳng.

Một đặc điểm chung của các lực lượng này đó là: đều có sự suy giảm trạng thái chức năng cơ thể sau quá trình thực hiện nhiệm vụ. Tuy nhiên mỗi lực lượng lại có sự suy giảm khác nhau phụ thuộc vào đặc điểm môi trường hoạt động của từng đơn vị; Cụ thể đối với bộ đội ra đa và thủy thủ tàu ngầm thì có sự giảm nhịp tim (đạt ý nghĩa thống kê) sau khi thực hiện nhiệm vụ, phi công quân sự ngược lại có chỉ số nhịp tim tăng lên sau khi thực hiện nhiệm vụ.

\section{KẾT LUÂ̂N}

- Các lực lượng bộ đội đặc thù có đặc điểm chung về điều kiện môi trường làm việc như: Tiếng ồn lớn, nhiệt độ cao, công việc vất vả và căng thẳng.

- Ngoài yếu tố chung về đặc điểm chung về môi trường làm việc, thì mỗi đởn vị riêng biệt có những yếu tố ảnh hưởng đặc trưng tác động lên sức khỏe của bộ đội đặc thù như sau:

+ Bộ đội radar: chịu ảnh hưởng mạnh mẽ của sóng radar

+ Phi công quân sự: Yếu tố ảnh hưởng lớn nhất là âm thanh lớn, nhiệt độ quá nóng

+ Thủy thủ tàu ngầm: không gian làm việc ngột ngạt, thiếu ánh sáng, có hơi khí độc và công việc căng thẳng.

\section{TÀI LIÊU THAM KHẢO}

1. Зимкина А. М., Нейрофизиологические исследования в экспертизе трудоспособности. - 
Л., «Медицина», 1978., 280 с.

2. Котляр Д.Л., Функциональное состояние организма лётчиков вертолётов морской авиации и направления его оптимизации, Саратовский научно-мед журнал, том 5, № 2, 2009, c. 215-217.

3. Đố Văn Hàm, Giáo trình Sức khỏe nghề nghiệp, NXB Y học, 2007.

4. Nguyễn Liễu (2010), "Nghiên cứu thực trang ô nhiếm môi trường lao động và sức khỏe bệnh tât của công nhân tại một số nhà máy xí nghiệp quổc phòng", Y học lao động và vệ sinh môi trường, số 13.
5. ACGIH (1991), "Applied occupational enviromental hygiene", Elsevier sciene Inc. New York.

6. Hartmut Ising, Wolfgang Babisch, Barbara Kruppa.Noise-induced endocrine effects and cardiovascular risk, Noise \& Health, 1999. Vol. 1, №. 4. P. 37- 48.

7. Lê Trung (2000), Bệnh nghề nghiệp, tập III trang 335-343.

8. Колганов А.В., Марьенко Л.В., Гигиена труда и профессиональные заболевания., 1977., № 9 (сентябрь)., С. 41-43., ISSN 0016-9919.

\section{VAI TRÒ CỦA X-QUANG THƯỜNG QUY TRONG CHẨN ĐOÁN THOÁI HOÁ KHỚP GỐI TIÊN PHÁT}

\section{TÓM TẮT}

Nghiên cứu được tiến hành trên 76 bệnh nhân thoái hoá khớp gối tiên phát, giai đoạn II, III, đến khám và điều trị tại bệnh viện Việt. Mục tiêu: mô tả một số đặc điểm hình ảnh X-quang thường quy của bệnh nhẩn thoái hoá khớp gối tiên phát. Pháp nghiên cứu: Bênh nhân được chup X-quang khớp gối theo hai bình diện thẳng và nghiểng với tư thế đứng có tỳ trọng lượng. Mức độ thoái hoá khớp được đánh giá theo tiêu chuẩn Kellgren- Lawrence, mô tả tổn thương theo thang điểm của OARSI. Kết quả: Gai xương có ở tất cả bệnh nhân. Hẹp khe khớp, đặc xương dưới sun và biến dang đầu xương lần lượt chiếm tỷ lệ $82,6 \%, 76,1 \%$ và $60,9 \%$. Nhóm thoái hoá đô II có điểm từ 1,5-2 theo OARSI, trong khi đó đối với nhóm thoái hoá độ III, số điểm từ 2,2-2,7. Kết luận: Mặc dù việc sử dụng rộng rãi phương pháp siêu âm khớp và chụp cắt lớp hoặc cộng hưởng từ trong thực hành lâm sàng, song chụp $X$ quang khớp gối thổng thường vẫn là tiêu chuẩn "vàng" để đánh giá tình trang thoái khớp gối.

Tư khoá: Thoái hoá khớp gối, X-quang khớp gối, gai xương

\section{SUMMARY \\ ROLE OF ROUTINE X-RAY IN DIAGNOSIS OF PRIMARY KNEE OSTEOARTHRITIS}

The study was conducted on 76 patients with primary knee osteoarthritis, stages II, III, who came for examination and treatment at VietDuc Hospital. Objectives: Describe some routine X-ray imaging characteristics of the patients. primary knee osteoarthritis. Method: The patient was X-rayed of the knee joint in both posteroanterior lateral and view

${ }^{1}$ Đại Học Y Hà Nội,

${ }^{2}$ Bênh viên HN Việt Đức

Chịu trách nhiệm chính: Dương Đình Toàn

Email: duongdinhtoan@hmu.edu.com

Ngày nhận bài: 23.8.2021

Ngày phản biên khoa họ: 14.10.2021

Ngày duyệt bài: 25.10.2021

\section{Dương Đình Toàn" ${ }^{1,2}$}

with a standing position with weight bearing. The degree of osteoarthritis was assessed according to the Kellgren-Lawrence criteria, describing the damage according to the OARSI scale. Results: Bone spurs were present in all patients. Joint space, subchondral bone thickening and bone head deformity accounted for $82.6 \%, 76.1 \%$ and $60.9 \%$, respectively. The grade II degenerative group has a score of 1.5-2 according to OARSI, while for the group with grade III degeneration, the score is from 2.2-2.7. Conclusion: Despite the widespread use of joint ultrasonography and magnetic resonance tomography in clinical practice, conventional radiography of the knee remains the "gold" standard in the contemporary assessment of osteoarthritic knee.

Key words; radiography, osteoarthriti, bone spurs

\section{I. ĐẶT VẤN ĐỀ}

$X$-quang thường quy vẫn là tiêu chuẩn "vàng" trong đánh giá thoái hóa khớp gối (THKG). X-quang là hình chiếu hai chiều của cấu trúc khớp gối ba chiều. Những thay đổi trên phim X-quang bao gồm hẹp khe khớp, hình thành các gai xương, đặc xương dưới sụn và u nang, biến dạng đầu xương. Những thay đổi này xảy ra trong các giai đoạn phát triển khác nhau của bệnh thoái hóa khớp và được phản ánh trong các thang điểm đánh giá bán định lượng. Một trong những thang điểm được sử dụng phồ biến nhất là thang điểm được tạo ra bởi Kellgren và Lawrence vào năm 1957, trải qua nhiều lần sửa đổi theo thời gian. Một atlas của Hiệp hội Nghiên cứu viêm thoái hoá khớp Quốc tễ (OARSI) đưa ra một cách tiếp cận khác để đánh giá mang tính định lượng, chi tiết hơn, dựa trên khảo sát các hình ảnh thoái hoá ở các vùng khác nhau của khớp gối. Đo khoảng cách giữa ranh giới xương đùi và xương chày là phương pháp định lượng phổ biến nhất để đánh giá thoái hóa khớp gối. Một trong những nhược điểm chính 